تأثير كم آبيارى، روش كشت و خاكيوش بر محصول و بهرهورى آب گياه ماش

مريم عسكرى'، على اكبر كامكار حقيقى '*" عليرضا سياسخواه'، فاطمه رزاقى' و مجيد رخشندهرو'

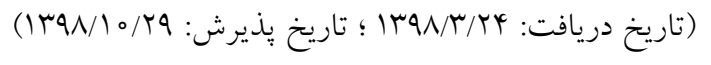

جكيده

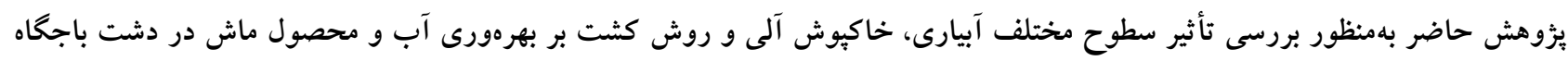

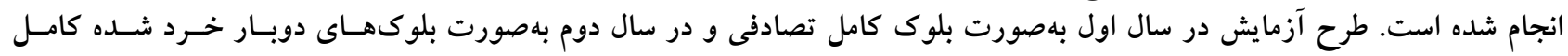

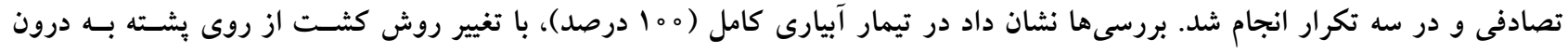

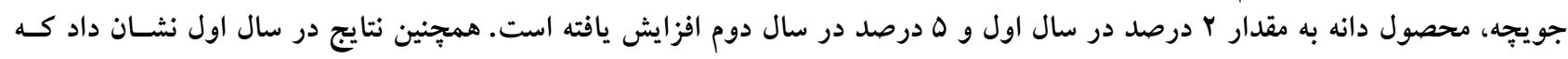

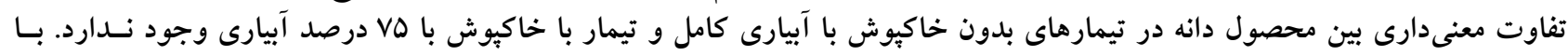

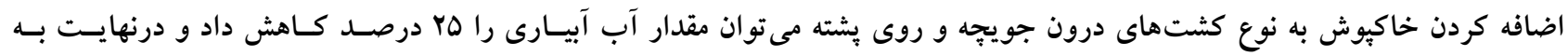

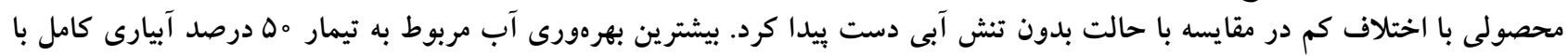

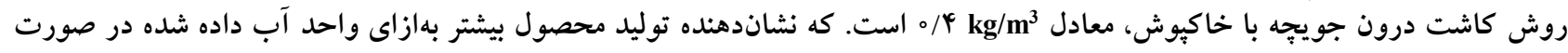

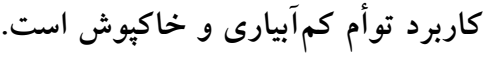

وازمهاى كليدى: كمآبيارى، خاكيوش، روش كاشت، ماش 
كَاه مىشود (Yr). از جمله مو ادى كه بهعنوان خاكيوش از آنهـا

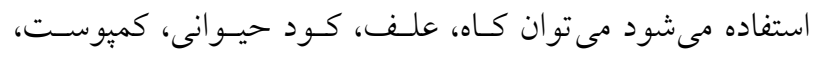

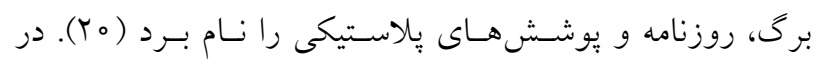

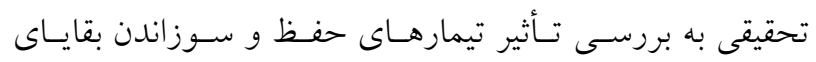

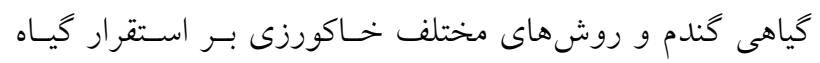

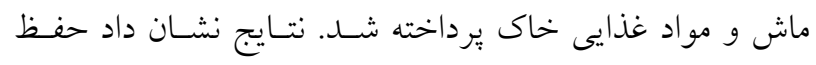
بقاياى كندم باعث كـاهش جـرم مخصـوص ظـاهرى خـاك در عمق ها-ه سانتى مترى و همجنين افزايش نفوذيذيرى خاك در

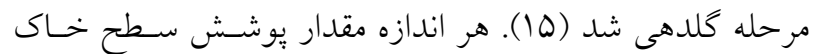
توسط خاكيوشهاى طبيعى افزايش ييدا كند، بههمان اندازه نيـز

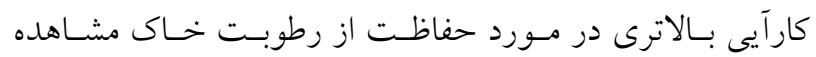
مى شود. همجنين افزايش مقدار خاكيوشهـاى كلشى بـهدليـل

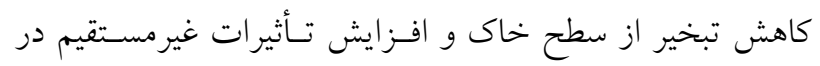
كنترل علفهاى هرز باعث افـزايش بيشـتر محصـول مسى شـود

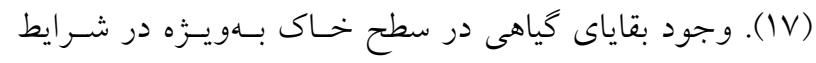

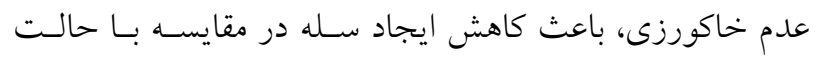

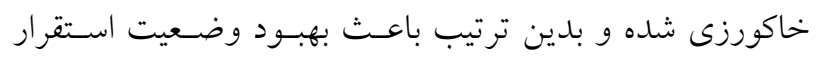

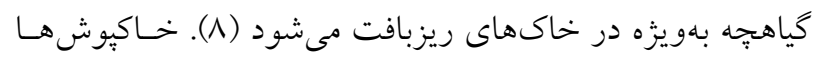

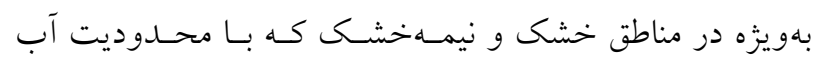

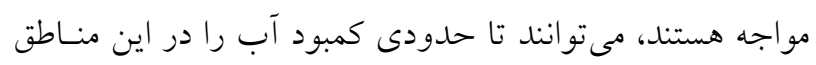

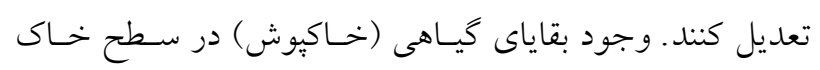

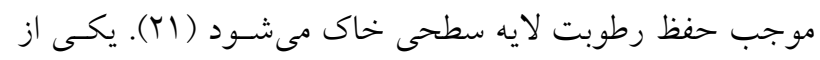

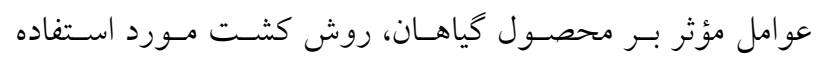

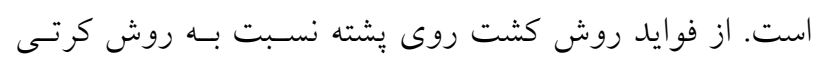

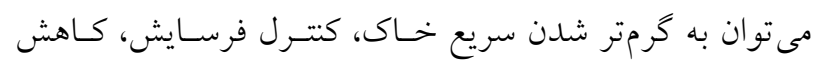

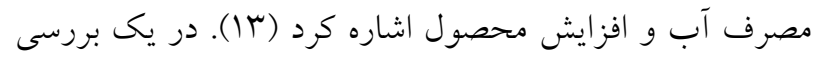

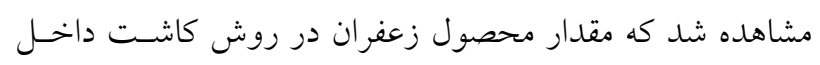

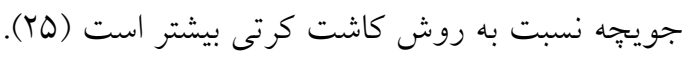

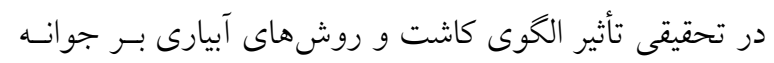

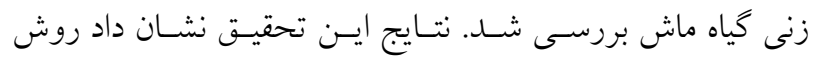

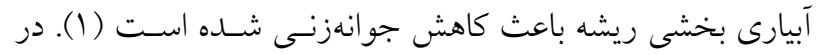

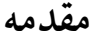

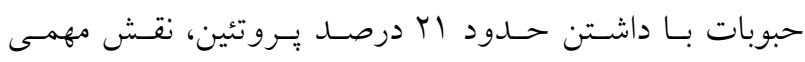
در تأمين نياز غذايى بشر داشته و مكمل غذايى طبيعى محسوب

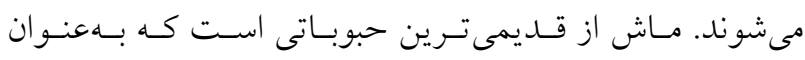

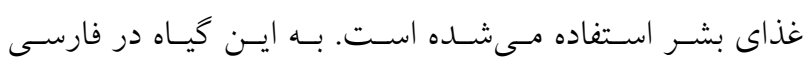

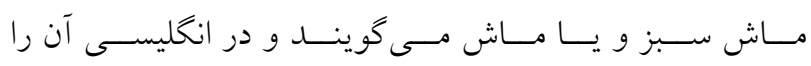
gung bean ، Green gram

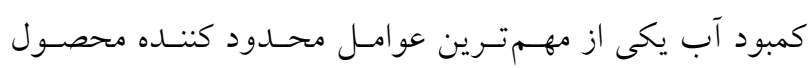

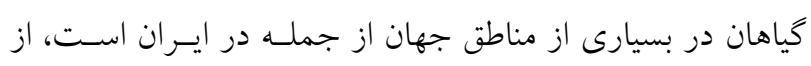

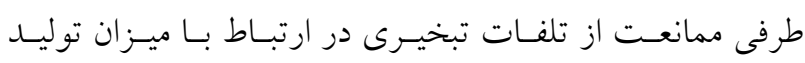
محصول و مصرف بهينه آب حائز اهميت است. امروزه بـهدليـل

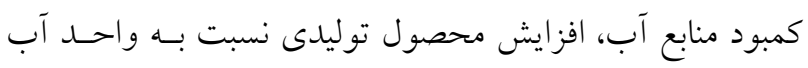

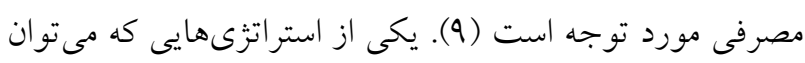

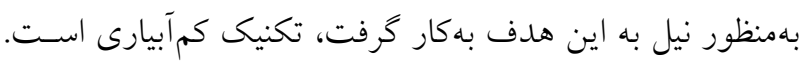

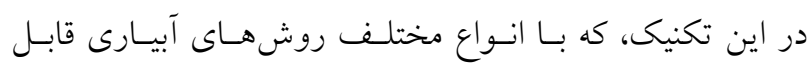

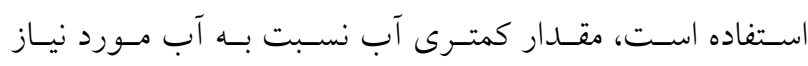

بهصورت مديريت شده در اختيار كياه قرار داده مى شود (م (1).

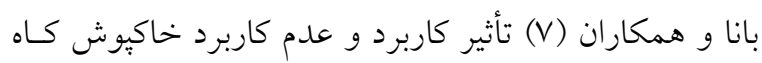

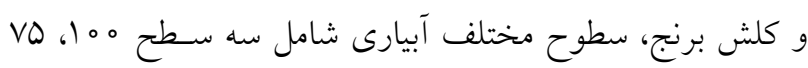

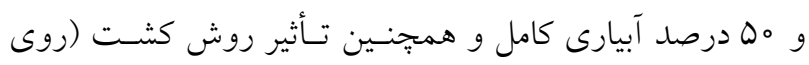
هشته و كف جويجهه) بر محصول مـاش را مـورد ارزيـابى قـرار

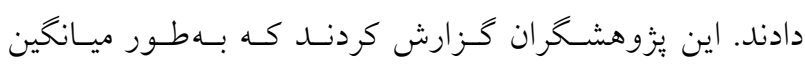

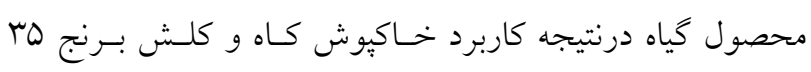
درصد افزايش يافت. در يزوهشى ديخر تأثير كودهاى نانو كلات

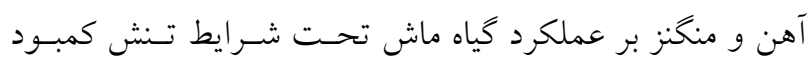

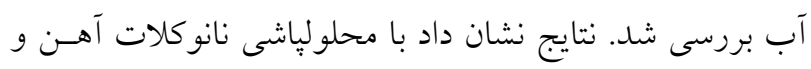

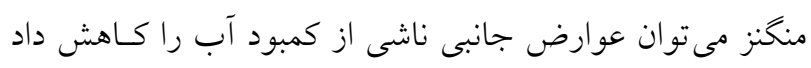

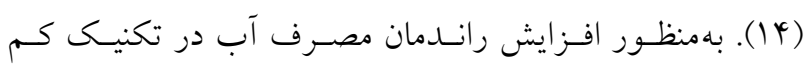

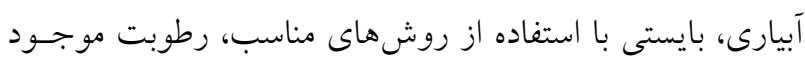

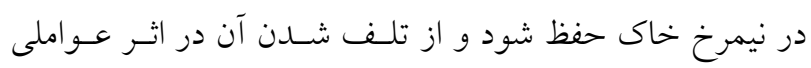

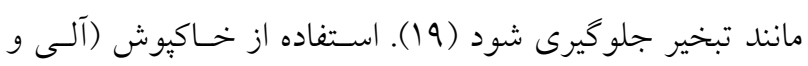

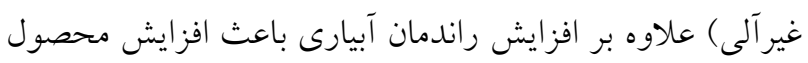


جدول 1. خصوصيات فيزيكى خاك در منطقه مورد آزمايش"*

\begin{tabular}{|c|c|c|c|c|}
\hline \multicolumn{4}{|c|}{ خصوصيات فيزيكى } & \multirow[b]{2}{*}{ عمق خاى (cm) } \\
\hline بافت خاى & $\begin{array}{c}\rho_{\mathrm{b}} \\
\left(\mathrm{g} \cdot \mathrm{cm}^{-3}\right)\end{array}$ & $\begin{array}{c}\text { PWP } \\
\text { (درصد حجمى) }\end{array}$ & 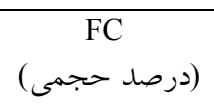 & \\
\hline لوم رسى سيلتى & $1 / 40$ & IV & rt & ro-o \\
\hline لوم رسى سيلتى & $1 / 4 V$ & 19 & س & q०-ro \\
\hline
\end{tabular}

افزايش راندمان كاربرد آب و محصول كيـاه را بـهدنبـال داشـته

با توجه به اهميت زراعى و اقتصادى ماش بلهعنوان يكسى از

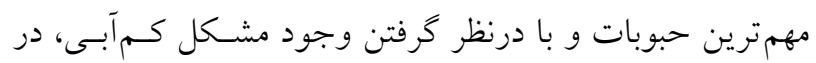

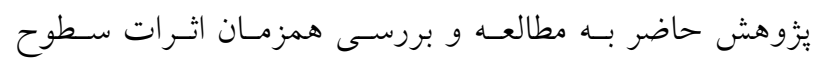

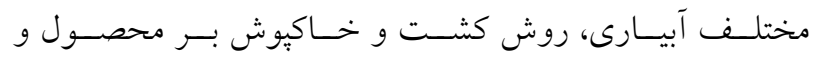
بهرهورى آب در گياه ماش يرداخته شد.

\section{مواد و روشها}

اين يزوهش در مزرعـه تحقيقساتى دانشـكده كشـاورزى دانشـاه شيراز واقع در فاصله 9 أكيلومترى شمال شرقى شـيراز در دشـت

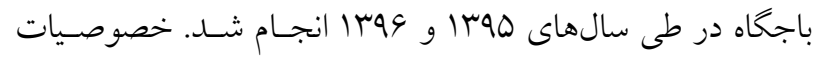
فيزيكى خاك منطقه مورد آزمايش در جدول آلوآورده شده است.

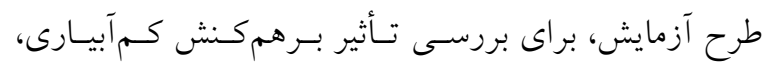
روش كشت و خاكيوش كاه و كلـش گذنـدم بـر محصـول كيـاه ماش، در سال اول بلوك كامل تصـادفى و در سـال دوم، كـرت دوبار خرد شده در قالب بلوى كامل تصادفى و در هر دو سـال

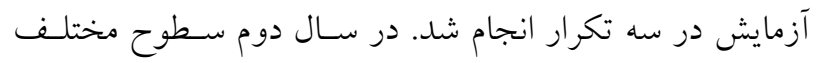

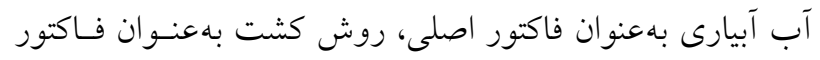

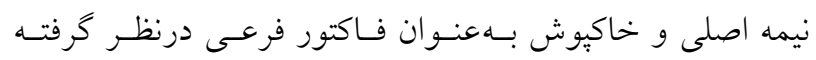

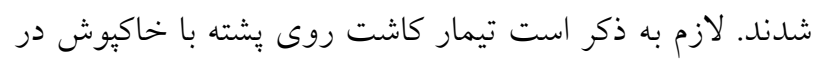

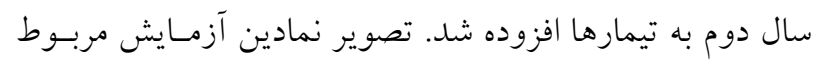

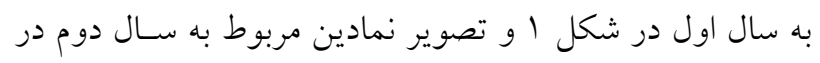

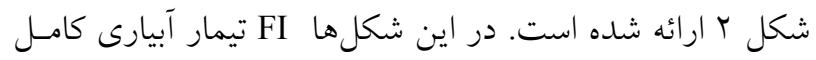

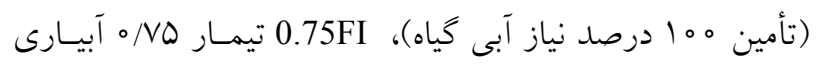

يزوهشى تأثير تيمارهاى مختلف كم آبيارى بر محصول دانه ارقام

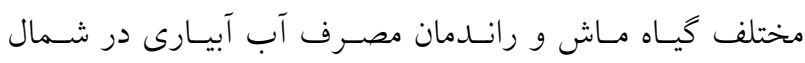

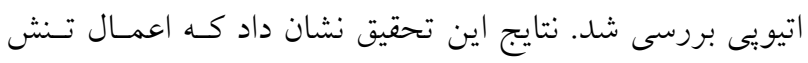

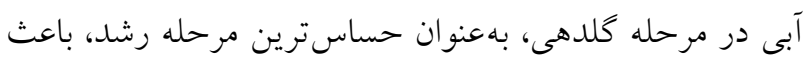

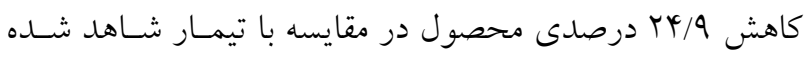

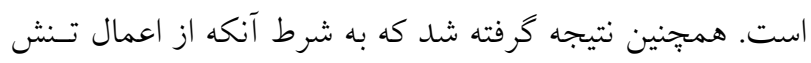

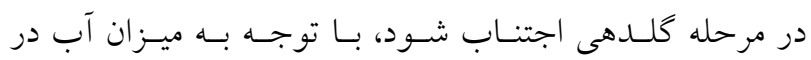
دسترس، مىتوان تنش آبى را در ديخر مر احل رشد اعمـال كـرد

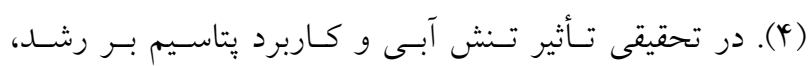

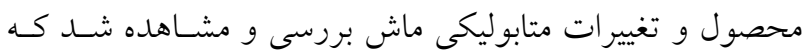
وزن خشك، وزن تر و محصول دانه ماش تحت تيمارهاى تنش لت

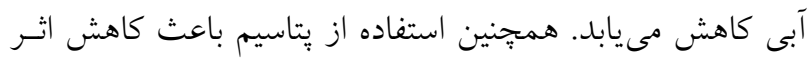

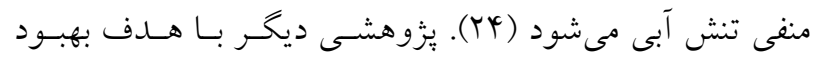

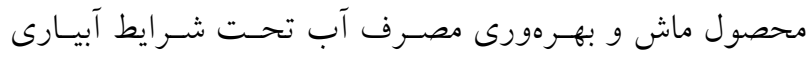

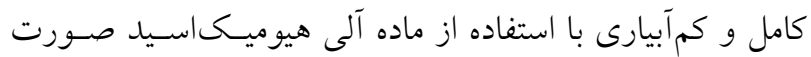
كرفت. نتايج نشان داد اخـتلاف معنسى دارى در محصـول دانـه،

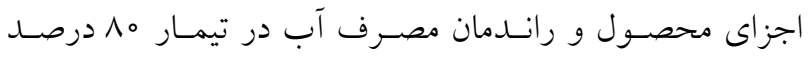

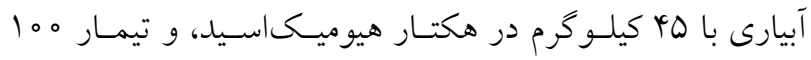

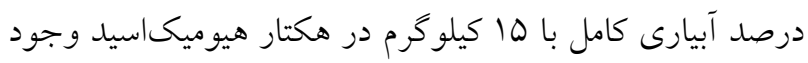

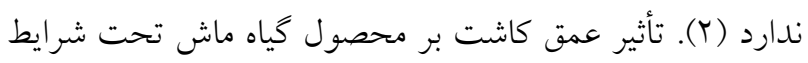

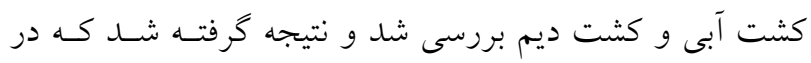

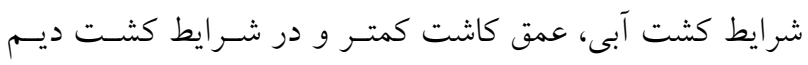
عمق كاشت بيشتر باعث بهبود محصول و اجزاى محصول كيـاه

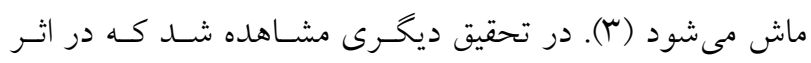

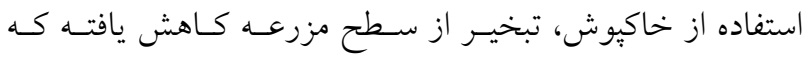


نشريه علوم آب و خاك / سال بيست و جهارم / شماره سوم / باييز 9هب1

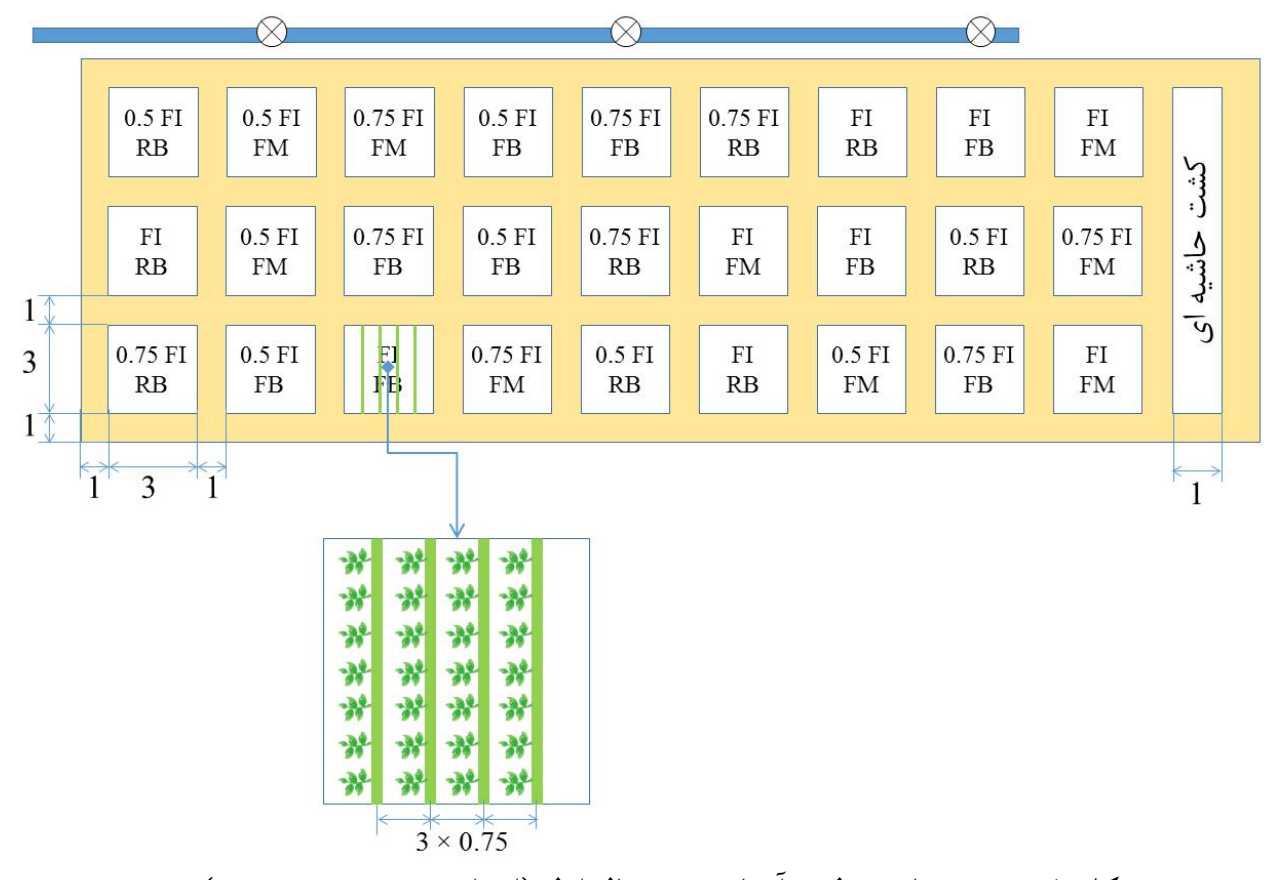

شكل ا. تصوير نمادين طرح آزمايش در سال اول (اعداد برحسب متر هستند.)

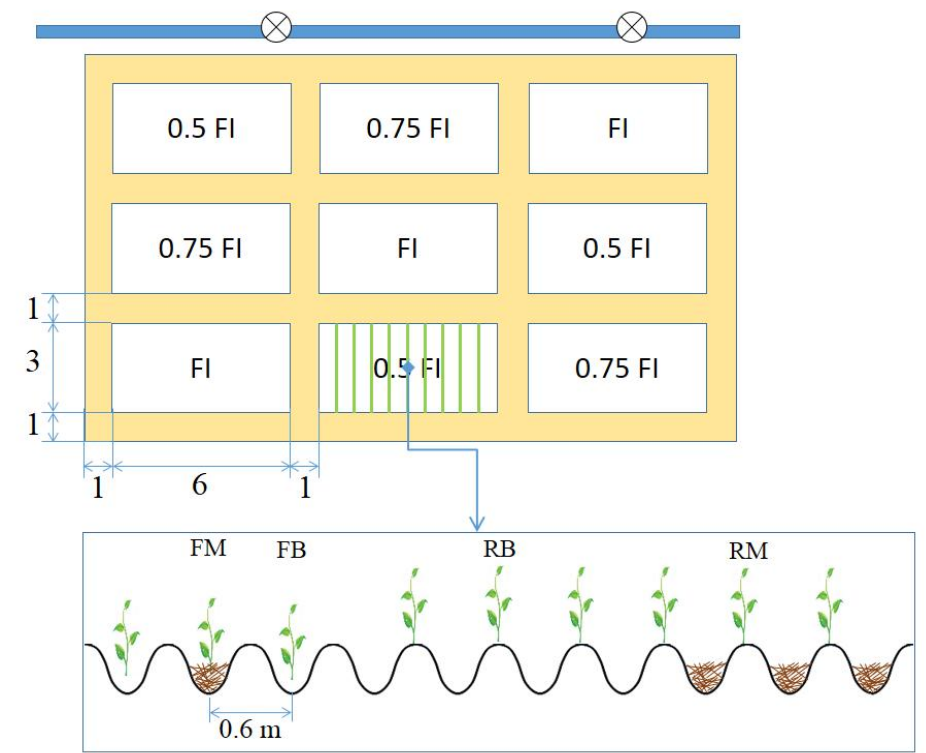

شكل r. تصوير نمادين طرح آزمايش در سال دوم (اعداد برحسب متر هستند.)

كامل، 0.5FI تيمار ه/ آبيارى كامـل، F تيمـار كشـت در كـف تيمارهاى نوع كشت عبارتنــ از: تيمـار كشـت در كـف جويجهـه و

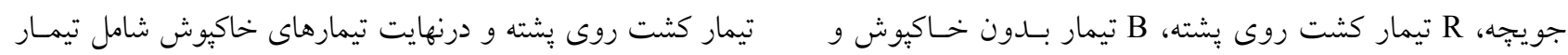
بلدون خاكيوش و تيمار داراى خاكيوش به مقدار ه التن در هكتـار M

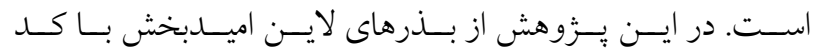
تيمارهاى آبيارى در هر دو سـال مطالعـه شـامل تيمـار آبيـارى

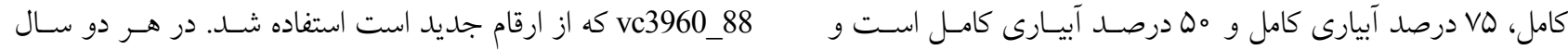


ريشه برحسب درصد اسـت. عمـق توسـعه ريشـهـ در روزهـاى مختلف يُ از كاشت از معادله زير محاسبه شد (9): $\mathrm{Rd}=\operatorname{Rdmax}\left[\frac{1}{2}+\frac{1}{2} \sin \left(3.03 \frac{\mathrm{Dag}}{\mathrm{Dtm}}-1.47\right)\right]$ كه در آن Rd عمق توسعه ريشه (cmax Rdmax عمـق توسـعه ريشه در زمان حداكثر رشد گياه (cm)، Dag تعـداد روز بعـد از جوانهزنى (day) و Dtm تعداد روز از زمان جوانهزنى تـا زمـان حداكثر عمق مؤثر كياه (day) است. حداكثر مقدار عمـق ريشـه در تحقيـق حاضـر معـادل 09 سـانتىمتـر درنظــر كرفتـه شـد. بهرهورى آب آبيارى نيز از معادله زير محاسبه شد: $\mathrm{IWP}=\frac{\mathrm{Y}}{\mathrm{W}}$

كه در آن IWP مقدار بهرهورى آب آبيـارى (kg/m³)، Y محصول دانه (kg/ha) و Wقدار آب آبيارى در كل دوره رشد كياه (m³/ha) است. محصول كـه شـامل دانـههـاى مـاش اسـت از كـرتهـا بهاصورت دستى برداشت شد. عمليات برداشت نمونـه بـراى تعيين وزن ماده خشك توليــ شــه بـهـهـورت دسـتى و بـا

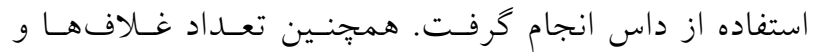
تعداد دانه در هر غلاف بهصورت دستى شمارش و بر اساس آن وزن هزاردانه گياه ماش در هر تيمار مشخص شد. يس از اتمام مرحله برداشت محصول، قسمت هاى هو ايى تيمارهـاى مختلف براى تعيين مقدار ماده خشك برداشـت شـد. آنـاليز دادهها با استفاده از نـرمافـزار SAS انجــام شــــ همـينطـور مقايسه ميانخينها بـا اسـتفاده از آزمـون دانكـن و در سـطح احتمال ه درصد انجام شد.

\section{نتايج و بحث} مقادير آب آبيارى در تيمارهاى مختلف در سالهـاى مـورد مطالعـه در جدول ب ارائه شده است. مقادير ميانخين محصول دانه مـاش در تيمارهاى مختلف در هر دو سال مورد مطالعسه در جــدول ب آورده شده است. نتايج نشان مىدهد كـه بـا م و و مه درصــ كـاهش در مقدار آب آبيارى در تيمار كشت روى بشته، محصول دانه بهترتيـب

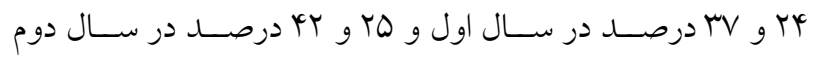

ميزان •ها كيلوكرم در هكتار كود آمونيوم فسفات بهمنظور تقويــت زمين در زمان شخم به زمين داده شد. كاشت بذر بهصورت دستى

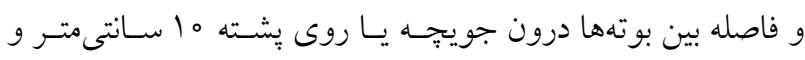
عمق كاشت ب-Y سانتى متر درنظر گرفتــه شـــ. بــر اسـاس توصسيه

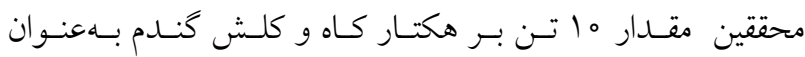
خاكيوش بهصورت دستى درون كرتها (كف جويجهـهــا) توزيـع شد (ه). با توجـهـ بـهـ اينكـهـه فاصـله رديـفـهـا در سـال اول و دوم بهترتيب VD و و9 سانتى متر لحاظ شــده اسـت، تـراكم بوتـهـهـا در

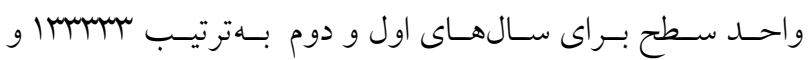
$19999 \mathrm{~V}$

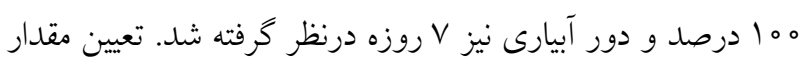

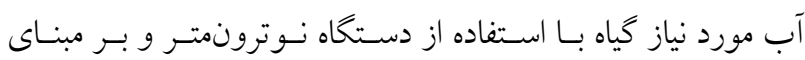
رساندن اين رطوبت تا عمق ريشه به حد ظرفيـت زراعسى مزرعـه، انجام شد. در اين يُزوهش از روش آبيارى جويخهاى استفاده شد و همينطور آب با استفاده از كتتور حجمى در كـرتهـا توزيـع شـــ. مقادير آب آبيارى در تيمارهاى مختلف در سالهـاى مـورد مطالعـه. در جدول آ آورده شده است. تبخير - تعرق واقعى كياه بـا اسـتفاده از معادله بيلان آب در خاى (معادله () محاسبه شد:

$\mathrm{I}+\mathrm{R}= \pm \Delta \mathrm{s}+\mathrm{ET}_{\mathrm{c}}+\mathrm{Dp}$

كه در آن، ETc تبخيـر - تعـرق واقعى گيـاه در مزرعـه برحسـب ميلىمتر، I مقدار آب آبيارى برحسب ميلىمتر، R مقدار بارنـدكى در فاصله اندازهگيرى آب خاى برحسب ميلىمتـر، sه تغييـرات ذخيره رطوبت خاى كه با استفاده از اندازهذيـرى رطوبـت خـاى قبل از آبيارىهاى متوالى بهدست آمده برحسبب ميلى متـر و Dp مقدار نفوذ عمقى برحسب ميلىمتر است. بر اساس قانون دارسى مقدار نفوذ عمقى برابر هدايت هيدروليكى غيراشباع منظـور شـد. بنابراين مقدار نفوذ عمقى با استفاده از معادله زير كه براى منطقـه

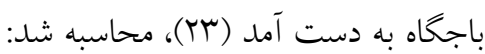
$\mathrm{K}(\theta)=2.715 \times 10^{-19} \mathrm{e}^{(1.1) \times \theta}$ كه در آن ( K( هدايت هيدروليكى خـاك غير اشـباع در ناحيـه يايين تر از عمق توسعه ريشه (نفوذ عمقى) برحسب سانتى متر بر روز و \رطوبت حجمى خاك در ناحيه پيايينتر از عمق توسعه 
جدول r. مقادير آب آبيارى در تيمارهاى مختلف در سالهاى مورد مطالعه (m²/ha)

\begin{tabular}{|c|c|c|c|c|c|}
\hline \multicolumn{4}{|c|}{ روش كاشت } & \multirow{3}{*}{ تيمار آبيارى } & \multirow{3}{*}{ سال } \\
\hline \multicolumn{2}{|c|}{ كاشت روى يشته } & \multicolumn{2}{|c|}{ كاشت درون جويجֶه } & & \\
\hline \multirow[t]{4}{*}{ با خاكيوش } & بدون خاكيوش & با خاكيوش & بدون خاكيوش & & \\
\hline & YOVV & 4190 & FYYO & $\mathrm{FI}^{*}$ & \\
\hline & rVGG & ryor & MGYA & $\circ / V \Delta F I$ & 11490 \\
\hline & $r 900$ & TVYV & rAVV & $\circ / \mathrm{DF}$ & \\
\hline GYSV & FTEV & GTEV & FYEV & FI & \\
\hline rسטr & سחסץ & سזهr & سחסץ & $\circ / V Q F I$ & 11499 \\
\hline r人०。 & r人。o & Y人०。 & r人。o & $\circ / \mathrm{QFI}$ & \\
\hline
\end{tabular}

جدول r. مقادير ميانخين محصول دانه ماش در تيمارهاى مختلف در سالهاى مورد مطالعه (mg/ha)

\begin{tabular}{|c|c|c|c|c|c|}
\hline \multicolumn{4}{|c|}{ روش كاشت } & \multirow{3}{*}{ تيمار آبيارى } & \multirow{3}{*}{ 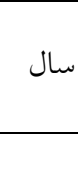 } \\
\hline \multicolumn{2}{|c|}{ كاشت روى يشته } & \multicolumn{2}{|c|}{ كاشت درون جويجֶه } & & \\
\hline با خاكيوش & بدون خاكيوش & با خاكيوش & بدون خاكيوش & & \\
\hline & $1 / T \wedge^{b}$ & $1 / 09^{a}$ & $1 / \Gamma 1 b^{*}$ & $\mathrm{FI}^{\text {麊 }}$ & \\
\hline & $\circ / 9 \wedge^{d}$ & $1 / T y b$ & $1 / 0 y_{c d}$ & $\circ / \mathrm{VQFI}$ & 1140 \\
\hline & $\circ /\left.\wedge\right|^{\mathrm{e}}$ & $1 / 10^{c}$ & $\circ / \wedge V^{e}$ & $\circ / \mathrm{FI}$ & \\
\hline$|/|^{a}$ & $1 / 0, b b$ & $1 / \mathrm{V}^{\mathrm{a}}$ & $1 / 1 Y^{b}$ & FI & \\
\hline $1 / 0 \mu^{c}$ & $\circ / \wedge \circ \mathrm{e}$ & $1 / \circ q^{b}$ & $\circ / \Lambda Y^{c e}$ & $\circ / \mathrm{VQFI}$ & 1499 \\
\hline$\circ /\left.\Lambda\right|^{e}$ & $0 / 9 Y^{g}$ & $\circ / 9 \circ d$ & $0 / 9 \Lambda^{\mathrm{f}}$ & $\circ / \mathrm{DFI}$ & \\
\hline
\end{tabular}

"در هر سال اعدادى كه داراى حداقل يك حرف مشترى هستند، در سطح ه درصد با آزمون دانكن داراى اختلاف آمارى نيستند.

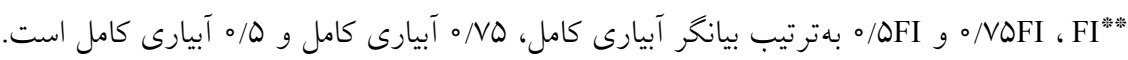

بررسى اثر كمآبيارى و كوددهى اركانيك بر كارايى مصـرف آب

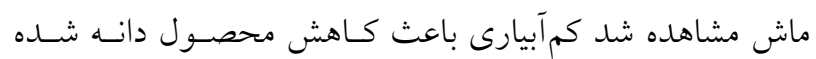
است.

در تيمار آبيارى كامل (ه ا درصــ)، بـا تغييـر روش كشـت از روى يشته به درون جويجيه، محصول دانه به مقدار Y درصــ در سال اول و ه درصد در سـال دوم افـزايش يافتـه اسـت. نتـايج آزمون آمارى در سال اول نشان داد كه تفـاوت معنسىدارى بــين

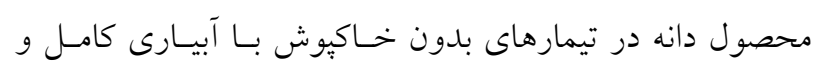

نسبت به تيمار آبيارى كامل كاهش مىيابد. درصورتى كه روش

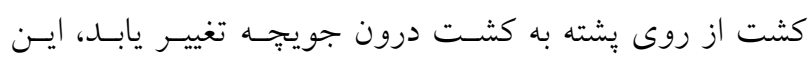
كاهش محصول بهترتيب 19 و rr درصد براى سال اول و ال و وب درصد براى سال دوم نسبت به تيمار آبيـارى كامـل خواهــ

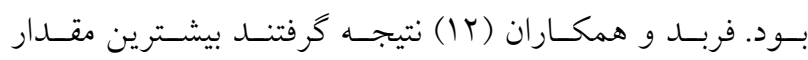
محصول دانه ماش مربوط به آبيارى كامل و كمترين مربـوط بـه

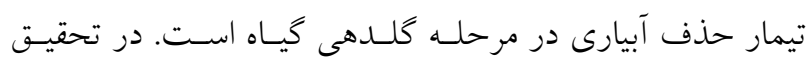
مشابهى كه توسط اسماعيليان و همكاران (11) انجام شد، ضمن 
درصد آبيارى و روش كشت درون جويجه با خاكيوش است كه

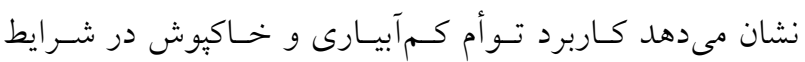
كمبود آب منجر به توليد محصول بيشتر بهازاى واحسـ آب دهاد داده

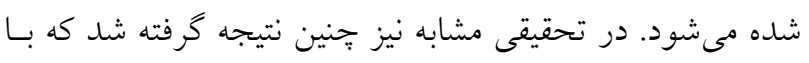
اعمال تنش خشكى در مرحله رشد رويشى كياه ماش مسى تسوان

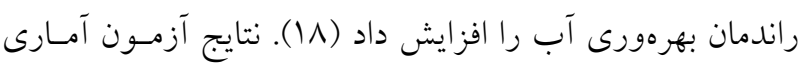

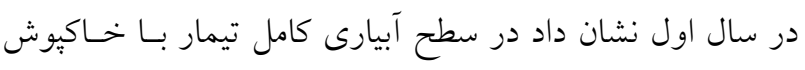
تفاوت معنى دارى با تيمارهـاى بــدون خـاكيوش داشـته اسـت.

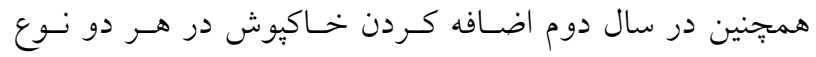

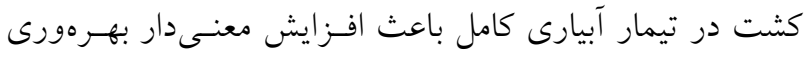

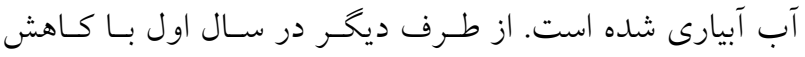

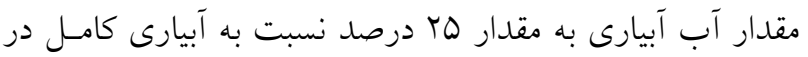
تيمارهاى كشت درون جويجهـه بـــون خـاكيوش و روى يشـته

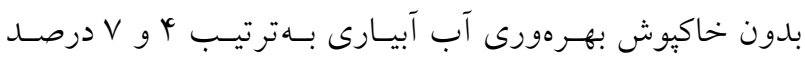
كاهش يافت كه اين تفاوت از نظر آمارى معنىدار نبود.

\section{نتيجه گيرى}

در اين تحقيق به بررسى برهمكنش كـمآبيـارى، روش كشـت و

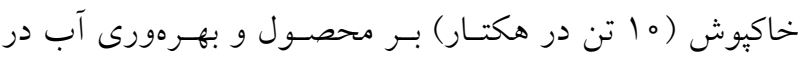

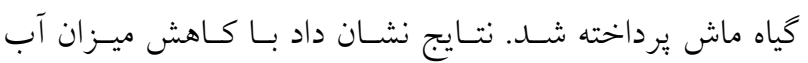

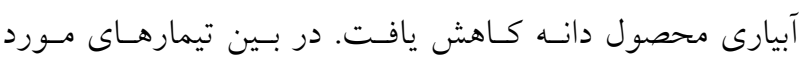
بررسى، اضافه كردن خاكيوش باعث افزايش معنسى دار محصـول دانه در هر دو سال شده است بهكونـهاى كـه محصـول دانسه در

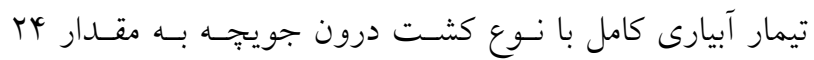

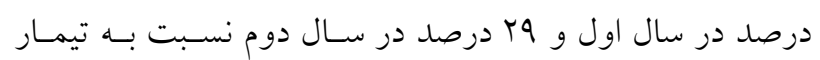
كشت روى يشته بدون خاكيوش در همين سطح آبيارى افزايش

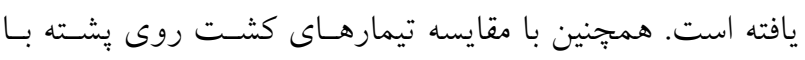

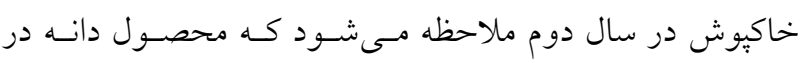

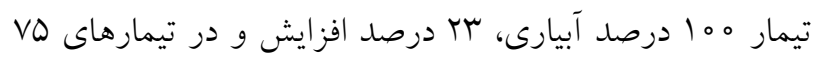

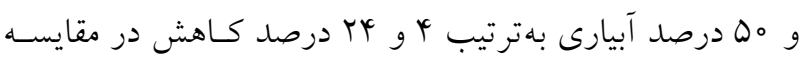

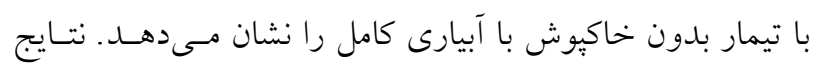

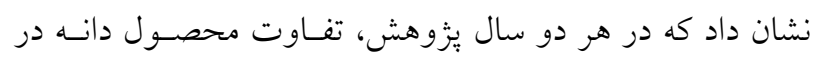

تيمار با خاكيوش با VD درصد آبيارى وجود نــدارد. همسينطـور

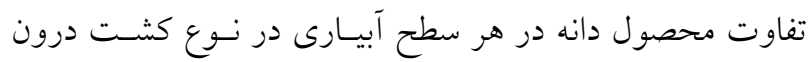

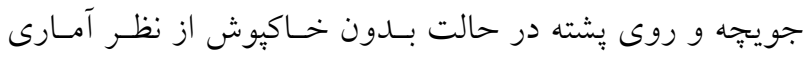

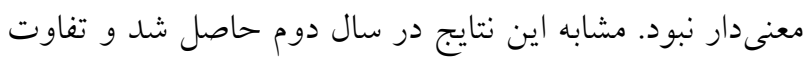
معنى دارى بين محصول دانه در تيمار درون جويجه با خاكيوش

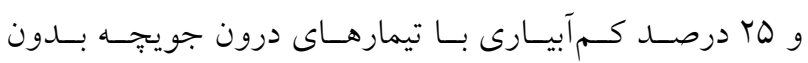

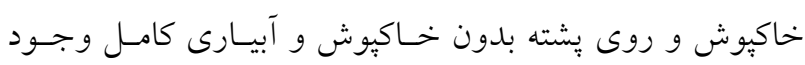

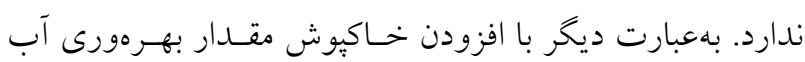
افزايش ييدا كرده است. بنابر اين ملاحظه مىشود با اضافه كـردن

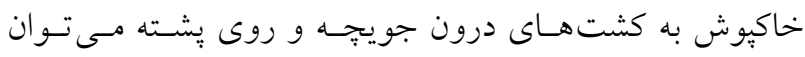

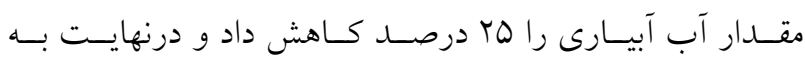

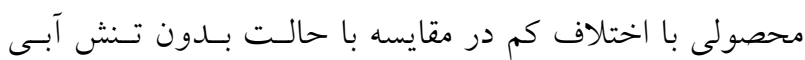

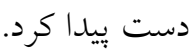
با توجه به جدول r نتايج حاصل از تيمارهاى داراى خـاكيوش نشان مىدهد كه محصول دانه در تيمار آبيارى كامل با كشـت درون

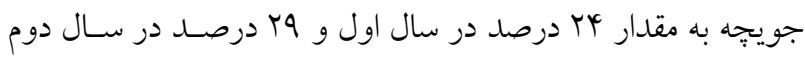

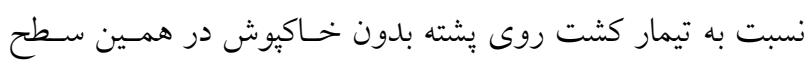

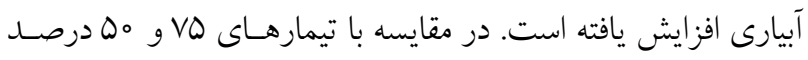

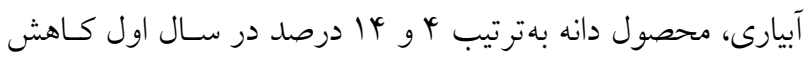

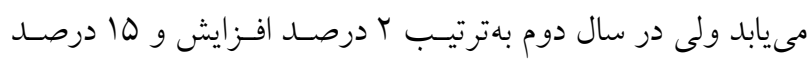

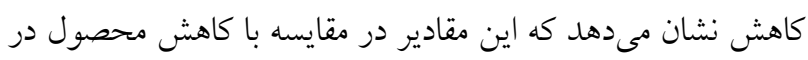

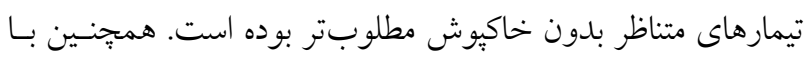

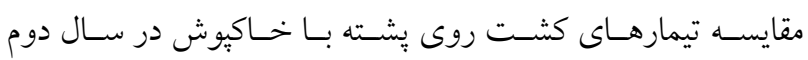

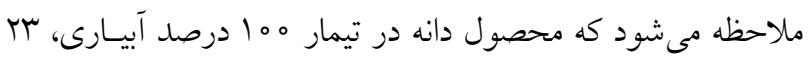

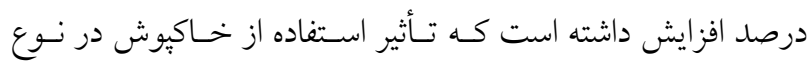

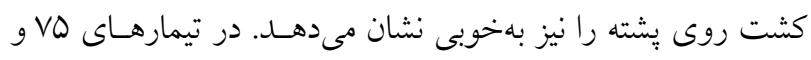

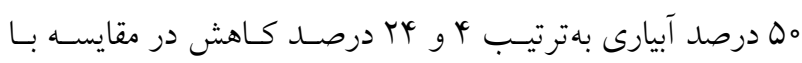
تيمار بدون خاكيوش با آبيارى كامل را نشان مىدهد. كه ايسن نتـايج با نتايج بانا و همكاران (V) مطابقت داشت.

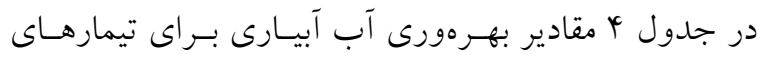

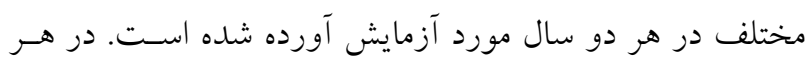

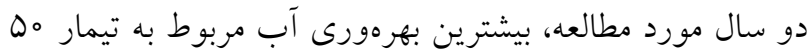


جدول f. بهرهورى آب در تيمارهاى مختلف در دو سال مورد مطالعه (kg/m³)

\begin{tabular}{|c|c|c|c|c|c|}
\hline \multicolumn{4}{|c|}{ روش كاشت } & \multirow{3}{*}{ تيمار آبيارى } & \multirow{3}{*}{ سال } \\
\hline \multicolumn{2}{|c|}{ كاشت روى يشته } & \multicolumn{2}{|c|}{ كاشت درون جويجه } & & \\
\hline با خاكيوش & بدون خاكيوش & با خاكيوش & بدون خاكيوش & & \\
\hline & $\circ / Y \Lambda^{\text {cde }}$ & $\circ / \wedge^{\mathrm{a}}$ & $\circ / \mu_{\circ} \mathrm{cd} *$ & $\mathrm{FI}^{\text {***; }}$ & \\
\hline & $0 /$ rGe & $\circ / \xi^{b}$ & $\circ / T \Lambda^{\mathrm{cd}}$ & $\circ / V \Delta F I$ & 11490 \\
\hline & $\circ \mu_{\circ}$ de & $\circ / \varphi_{\circ} \circ a$ & $\circ / \mu_{\circ} c$ & $\circ / \mathrm{DFI}$ & \\
\hline$\circ / I^{a}$ & $\circ / T Q^{c d}$ & $\circ M r^{a}$ & $0 / T \varphi^{c}$ & FI & \\
\hline $0 / T q^{b}$ & $0 /$ ruef & $\circ / T^{\mathrm{a}}$ & $\circ /$ Yyde & $\circ / \mathrm{V} \Delta \mathrm{FI}$ & 1499 \\
\hline$\circ / q^{b}$ & $0 / T T^{f}$ & $\circ / \mu r^{a}$ & $\circ /$ Yyde & $\circ / \Delta \mathrm{FI}$ & \\
\hline
\end{tabular}

"در هر سال اعدادى كه داراى حداقل يك حرف مشترى هستند، در سطح ه درصد با آزمون دانكن داراى اختلاف آمارى نيستند.

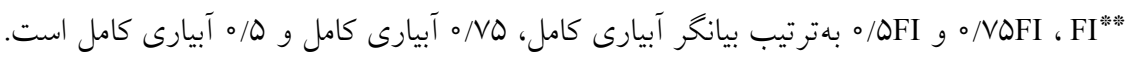

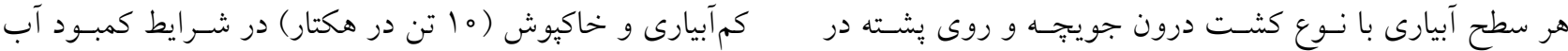

$$
\begin{aligned}
& \text { حالت بلدون خاكيوش از نظر آمارى معنى دارى نبـود بـهـجـز در است. } \\
& \text { تيمار •ه درصد آبيارى كه كشت درون جويجهه باعـث افـزايش }
\end{aligned}
$$

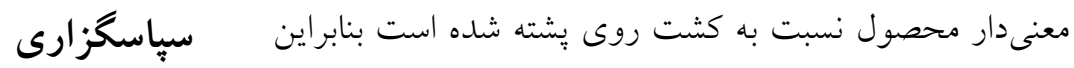

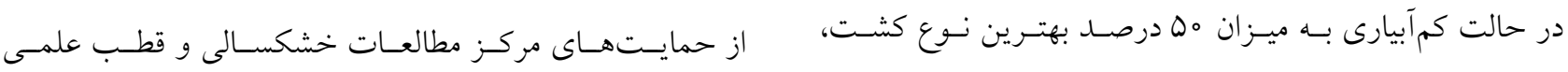

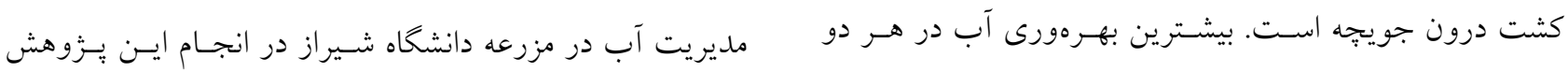

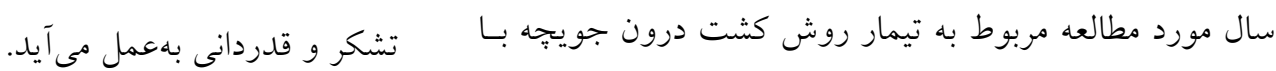

$$
\begin{aligned}
& \text { خاكيوش با •ه درصد كم آبيارى است كـه نشـاندهنـده توليــ }
\end{aligned}
$$

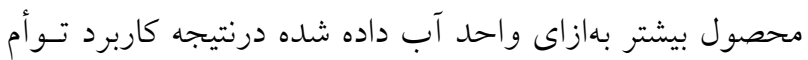

منابع مورد استفاده

1. Alizadeh-Amraie, A., A. Javanmard and H. Eskandari. 2019. Effect of planting pattern and irrigation method on germination of mung bean (Vigna radiate) harvested at different times of maturation. Iranian Journal of Seed Research 6(1): 51-63. (In Farsi).

2. Al-Shareef, A. R., F. S. El-Nakhlawy and S. M. Ismail. 2017. Enhanced mungbean and water productivity under full irrigation and stress using humic acid in arid regions. Legume Research 40: 1-5.

3. Amanullah, M., A. Muhammad, K. Nawab and A. Ali. 2016. Effect of tillage and phosphorus interaction on yield of mungbean (Vigna radiata L., Wilczek) with and without moisture stress condition. Ponte 72(2): 114-139.

4. Ambachew, S., T. Alamirew and A. Melese. 2014. Performance of mungbean under deficit irrigation application in the semi-arid highlands of Ethiopia. Agricultural Water Management 136: 68-74.

5. Baghbani, A. A., A. Kadkhodaie and S. S. A. M. Modarres. 2015. Effect of Wheat and Bean Residue along with Zinc Sulfate on Zinc and Iron Concentration and Grain Yeild of wheat. The Journal of Agricultural Science (University Of Tabriz) 25(3): 91-102

6. Borg, H. and D. W. Grimes. 1986. Depth development of roots with time: An empirical description. Transactions of the ASAE 29(1): 0194-0197. 
7. Bunna, S., P. Sinath, O. Makara, J. Mitchell and S. Fukai. 2011. Effects of straw mulch on mungbean yield in rice fields with strongly compacted soils. Field Crops Research 124(3): 295-301.

8. Cassel, D. K., C. W. Raczkowski and H. P. Denton. 1995. Tillage effects on corn production and soil physical conditions. Soil Science Society of America Journal 59(5): 1436-1443.

9. Davies, W. J., J. Zhang, J. Yang and I. C. Dodd. 2011. Novel crop science to improve yield and resource use efficiency in water-limited agriculture. The Journal of Agricultural Science 149(S1): 123-131.

10. English, M. 1990. Deficit irrigation. I: Analytical framework. Journal of Irrigation and Drainage Engineering 116(3): 399-412.

11. Esmailian, Y., M. B. Amiri, S. Askari Naeeni and F. Heidari. 2017. The effect of deficit Irrigation and Organic fertilization on increasing water use efficiency of mungbean in the hot and arid climate. The First National Conference of Applied Research in Science and Engineering. Mashhad. Eghbal Lahoori Educational and Research Institute. (In Farsi).

12. Farbod, N., A. Bakhshande and A. Aeenne Band. 2008. Effect of row spacing and non irrigation strategy on the yield and component of mungbeen. In $10^{\text {th }}$ Crop Science Society of Iran (CSSI) Congree. Seed and plant Improvement Institute, 19-22 Augest, Karaj, Iran. (In Farsi).

13. Griffith, D. R., S. D. Parsons and J. V. Mannering. 1990. Mechanics and adaptability of ridge planting for corn and soybean. Soil and Tillage Research 18: 113-126.

14. Izadi, Y. and S. Sanavey. 2018. Effect of nano iron and manganese fertilizers on mung bean growth and yield in water deficit stress condition. Field Crops Research 16: 651-664. 10.22067/gsc.v16i3.70133. (In Farsi).

15. Jamshidian, R., and M. R. Khajehpour. 1998. Effects of seedbed preparation methods on compaction and nutrients content of soil and on establishment of mungbean after wheat. The Journal of Water and Soil Science 2(3): 35-47. (In Farsi).

16. Li, F. M., P. Wang, J. Wang and J. Z. Xu. 2004. Effects of irrigation before sowing and plastic film mulching on yield and water uptake of spring wheat in semiarid Loess Plateau of China. Agricultural Water Managemen 67(2): 77-88.

17. Marcia, G., D. Rex and G. Martin. 2005. Practical Lessons Learned from the Sustainable Cotton Project Biological Agriculture Systems in Cotton (BASIC) Program. Sustainable Cotton Project, January 2005.

18. Moradi A, A. Ahmadi and A. Hossein Zadeh. 2008. Agro-physiological responses of mung bean (cv. Partov) to severe and moderate drought stress applied at vegetative and reproductive growth stages. The Journal of Water and Soil Science 12(45): 659-671. (In Farsi).

19. Mukherjee, A., M. Kundu and S. Sarkar. 2010. Role of irrigation and mulch on yield, evapotranspiration rate and water use pattern of tomato (Lycopersicon esculentum L.). Agricultural Water Management 98(1): 182-189.

20. Munn, D. A. 1992. Comparisons of shredded newspaper and wheat straw as crop mulches. Hort Technology 2(3): 361-366.

21. Sanford, J. O. 1982. Straw and Tillage Management Practices in Soybean-Wheat Double-Cropping. Agronomy Journal 74(6): 1032-1035.

22. Sarkar, S., M. Paramanick and S. B. Goswami. 2007. Soil temperature, water use and yield of yellow sarson (Brassica napus L. var. glauca) in relation to tillage intensity and mulch management under rainfed lowland ecosystem in eastern India. Soil and Tillage Research 93(1): 94-101.

23. Sepaskhah, A. R. and S. Ilampour. 1995. Effects of soil moisture stress on evapotranspiration partitioning. Agricultural Water Management 28(4): 311-323.

24. Tawfik, K. M. 2008. Effect of water stress in addition to potassiomag application on mungbean. Australian Journal of Basic and Applied Sciences 2(1): 42-52.

25. Yarami, Nand Sepaskhah, A. R. 2015. Saffron response to irrigation water salinity, cow manure and planting method. Agricultural Water Management 150: 57-66. 


\title{
The Effect of Deficit Irrigation, Planting Method and Mulch on the Yield and Water Productivity of Mungbean
}

\author{
M Askari' ${ }^{1}$ A. A. Kamgar-Haghighi ${ }^{*}$, A. R. Sepaskhah ${ }^{1}$, F. Razzaghi ${ }^{1}$ and \\ M. Rakhshandehroo²
}

(Received: June 1-2019; Accepted: January 31-2020)

\begin{abstract}
In the present study, the effects of different levels of irrigation, organic mulch and planting method on the mungbean yield in Badjgah were investigated. The experimental plan in the first year was full randomized block, while in the second year, it was full randomized split-split plot block design, in three repetitions. The results showed that in the FI treatments, the yield was increased up to $2 \%$ for the first year and $5 \%$ for the second year by changing the planting method from on over-ridge planting method to the in-furrow planting one. Also, the results of the first year showed that there was no significant difference between the yield in the fully-irrigated treatments without mulch and the treatment with mulch and 0.75 FI. The amount of the irrigation water could be decreased up to $25 \%$ by adding organic mulch in both planting methods, as compared to the fully-irrigated treatments without mulch. The maximum water productivity equal to $0.4 \mathrm{~kg} / \mathrm{m}^{3}$ was observed in $0.5 \mathrm{FI}$, in-furrow planting method with mulch treatment. It can be, therefore, concluded that the water productivity may be maximized with the application of both deficit irrigation and mulching strategies.
\end{abstract}

Keywords: Deficit irrigation, Mulch, Planting method, Mungbean.

1. Water Engineering Department, Shiraz University, Bajgah, Shiraz, Iran.

2. Agricultural \& Natural Resources Research \& Education Center of Fars Province.

*: Corresponding author, Email: akbarkamgar@yahoo.com 